\title{
Mortality rates in conflict zones in Karen, Karenni, and Mon states in eastern Burma
}

\author{
Thomas J. Lee', Luke C. Mullany², Adam K. Richards ${ }^{3}$, Heather K. Kuiper ${ }^{4}$, Cynthia Maung ${ }^{5}$ and Chris Beyrer ${ }^{2}$ \\ 1 Department of Medicine, University of California, Los Angeles, CA, USA \\ 2 Center for Public Health and Human Rights, Bloomberg School of Public Health, Baltimore MD, USA \\ 3 Department of Family \& Social Medicine, Montefiore Medical Center, Albert Einstein College of Medicine, Bronx, NY, USA \\ 4 Department of Public Health, University of California, Berkeley, CA, USA \\ 5 Backpack Health Worker Team, Mae Sot, Thailand
}

Summary

овJестіves To estimate mortality rates for populations living in civil war zones in Karen, Karenni, and Mon states of eastern Burma.

METHODS Indigenous mobile health workers providing care in conflict zones in Karen, Karenni, and Mon areas of eastern Burma conducted cluster sample surveys interviewing heads of households during 3-month time periods in 2002 and 2003 to collect demographic and mortality data.

RESULTS In 2002 health workers completed 1290 household surveys comprising 7496 individuals. In 2003, 1609 households with 9083 members were surveyed. Estimates of vital statistics were as follows: infant mortality rate: 135 (95\% CI: 96-181) and 122 (95\% CI: 70-175) per 1000 live births; under-five mortality rate: 291 (95\% CI: 238-348) and 276 (95\% CI: 190-361) per 1000 live births; crude mortality rate: 25 (95\% CI: 21-29) and 21 (95\% CI: 15-27) per 1000 persons per year.

CONCLUSIONS Populations living in conflict zones in eastern Burma experience high mortality rates. The use of indigenous mobile health workers provides one means of measuring health status among populations that would normally be inaccessible due to ongoing conflict.

keywords Burma, mortality, internally displaced persons, malaria, landmines, civil conflict

\section{Background}

The reliable assessment of morbidity and mortality in conflict zones is exceedingly difficult (Boss et al. 1994). Epidemiologists and international aid organisations, however, have begun to address this knowledge deficit. Several reports suggest that at a minimum, populations caught within the geographical confines of long-running conflicts undergo periods of very high mortality (Roberts \& Despines 1999; Assefa et al. 2001; Salama et al. 2001; Grein 2003; Gessner 1994). Unfortunately, the failure to overcome logistical, political, and methodological challenges to the measurement of mortality in conflict zones often results in little international attention being given to ongoing high mortality rates. Recent work, however, in Iraq (Roberts et al. 2004) and Sudan (Grandesso et al. 2005) demonstrate that even under extreme conditions, the impact of ongoing conflict on population-level health indicators can be described.

There are no published estimates of mortality rates from conflict areas of Burma, which has been the site of civil war for several decades, except for a single report relying on recently arrived refugees in Thailand as a source of measurement by proxy (Checchi et al. 2002) (Burma is also known as Myanmar. We use Burma throughout this report in accordance with the preference of the 1990 General Elector winner, the National League for Democracy). The Burmese government's so-called 'Four Cuts Policy', which cuts off the supply of food, funding, information, and recruits to ethnic minority insurgents, has also effectively prevented international assistance and assessment of health status. The World Food Program, which currently feeds more than $1 \%$ of Burma's population, reported that, although one-third of the children in Burma are suffering from malnutrition, 'they were being prevented by the junta from assessing a true national figure of those in need, which was likely to be much higher' (World Food Program 2004). Thus, although official Burmese national statistics reflect a widespread health crisis (Chelala 1998), they likely underestimate its true magnitude as they do not include conflict areas (UNICEF 2005). 
The Karen, Karenni, and Mon ethnic peoples living in conflict areas along the Thai-Burma border survive in what the Burmese military has declared 'free-fire' or 'black zones' in eastern Burma. War in these zones often forces villagers into hiding in the jungles as internally displaced persons (IDPs). Entire villages are also systematically displaced as a part of a military strategy for control of conflict-affected areas. By late 2004, there were an estimated 526000 IDPs in eastern Burma, and at least 240 villages had been destroyed, forcibly relocated, or abandoned in the two preceding years (Burmese Border Consortium 2004). IDPs and war-affected residents living in these zones rely upon a network of mobile indigenous health workers for basic healthcare known collectively as the 'Backpack Health Worker Team' (BPHWT), which also regularly collects health information. This paper presents population-based mortality estimates for conflict zones within Burma, and describes the methods used by mobile health workers to collect this data for otherwise unreachable populations.

\section{Methods}

\section{Design}

In 3-month time periods during 2002 (April-June) and 2003 (September-November), BPHWT health workers in conflict zones of Karen, Karenni, and Mon areas of eastern Burma conducted two retrospective household surveys of vital events in the 12 months before the interview. The BPHWT periodically conducts surveys on a variety of topics in order to gauge the coverage and impact of their health programs; these surveys represent recent attempts to measure mortality. The time periods were selected according to the monitoring needs of their programs, workload capacity, and logistical constraints; sampling had to occur when health workers were visiting villages during the course of their work.

Households were sampled from within the target area of the BPHWT, which includes approximately 125000 persons living in nine administrative areas (Figure 1). Village census information has been collected by BPHWT on an annual basis since 1999 by a combination of interviews with village heads and head counts, including age and gender groups. One hundred village-based clusters of 20 households each were randomly selected proportionate to village size. The cluster selection process was conducted separately for each year using renewed census information, and thus different villages were selected for each year.

The sample size (2000 for each survey) was calculated based on a balance of feasibility given the security and resource constraints of the field setting, and the need to estimate the primary outcome, infant mortality rate (IMR), with reasonable precision (within 50/1000 live births, assuming infant mortality rate $=150 / 1000$, crude birth rate $=40 / 1000$, mean household size $=$ six persons, overall survey completion rate $=85 \%$, and design effect $=2.0$ ).

Households were randomly selected within clusters by systematic sampling, visiting every $n$th household $(n=$ no. of households in village/20). A household was defined as a group of people who live in the same house and share meals. If the head of household was unavailable for two consecutive days, the next nearest household was selected. In order to minimise the bias from not reaching displaced villages, if an entire village had been displaced essentially intact, the interviewer attempted to locate the village and conducted the selection process in the same manner using family encampments instead of households. If displaced villages could not be accessed because of security reasons, then the nearest accessible village was selected.

\section{Implementation}

The design and implementation of the survey instrument was identical for each survey period. In workshops prior to each survey, mobile health worker supervisors were provided with training regarding interview techniques, sampling method, survey questions, case-definitions, and local translations. These supervisors trained interviewers within their mobile medical teams and directly supervised the interviewers in the field. The interviewers spoke the same language as respondents in most instances, but used a local translator if necessary. Respondents were assured of confidentiality, verbal consent was requested before initiating the survey, and no identifying information was recorded on the survey form. The survey included a household census and questions regarding all births and deaths occurring within the previous 12 months. Interviewers were trained to help respondents anchor their recall period by referring to important local dates or events. Age and sex were recorded for each living person in the household. For each reported death, respondents chose from a list of causes of death, which included malaria, diarrhoea, pregnancy-related, landmine, violence, and 'other' causes.

\section{Analysis}

Infant (IMR) and under-five (U5MR) mortality rates were estimated as a ratio of deaths to live births, while crude and age-specific mortality rates (CMR) were estimated as a ratio of all deaths to mid-year population. Cluster identification information for calculating the design effects of cluster sampling and adjusting the confidence intervals 


\section{T. J. Lee et al. Mortality in eastern Burma}

Figure I Map of Karenni, Karen (subdivided), and Mon areas.

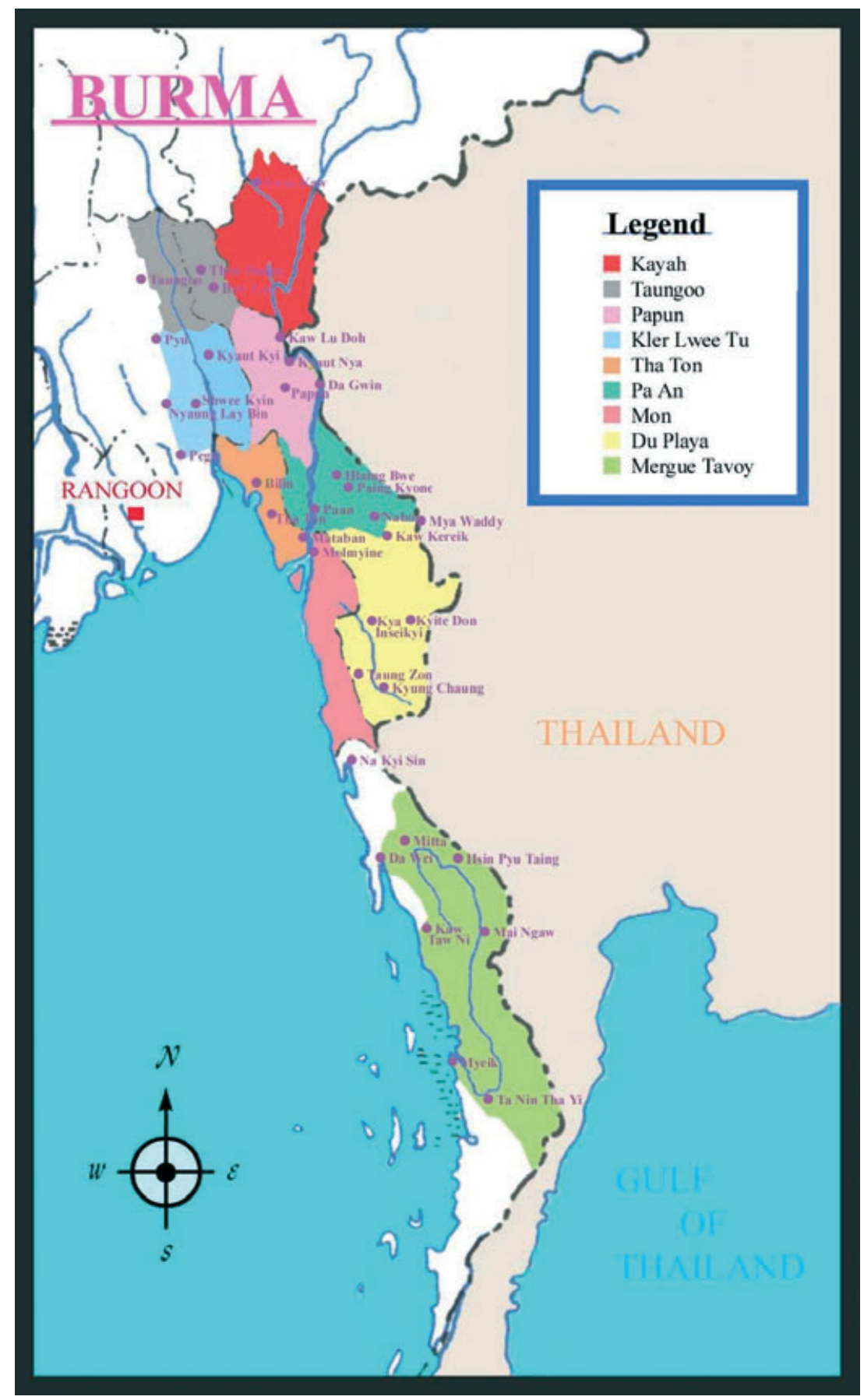

accordingly was only recorded for 2003. Therefore, design effects for these measures were estimated for 2003 but applied to both 2003 and 2002 to account for the clustersample design, and to improve the degree to which the two surveys were comparable.

\section{Ethical approval}

Local leaders of the Burma Medical Association and the National Health and Education Committee of the National Coalition of the Union of Burma (Government-in-Exile) 
reviewed and approved the survey protocol. The Johns Hopkins University Committee on Human Research approved the secondary analysis of the data. The authors of this paper were responsible for the secondary analysis, conducted with Stata 7.0 (Stata Corp., College Station, TX, USA).

\section{Results}

\section{Cluster and household characteristics}

The health workers completed and returned surveys from $1290(64.5 \%)$ households in 2002, increasing to 1609 $(80.5 \%)$ in 2003 . In 2003 , health workers reached 81 of 100 chosen clusters $(81 \%)$ because of security concerns, and two additional clusters were substituted in instances where the selected villages had been completely displaced. Among these 83 clusters, the overall response rate was $96.9 \%$, indicating that almost all the loss of sample was because of clusters that could not be reached. In both survey periods, the fewest surveys were returned from remote, highly insecure areas where travel time on foot for the health workers exceeds 1 month. In the 2002 period, the number of clusters lost was likely higher given the overall lower response rate, but specific information about clusters was not collected.

Characteristics of households and the overall sample populations are shown in Table 1. The 2002 survey documented $1382(18.4 \%)$ children $<5$ years of age and 7496 total persons, with an average household size of 5.8 persons. For 2003, among 9083 total persons, the proportion $<5$ years $(20.4 \%)$ and average household size (5.6) was not statistically different compared with the previous period.

Table I Numbers of clusters and households sampled and demographic characteristics for 2002 and 2003 survey periods

\begin{tabular}{lcc}
\hline Sample & 2002 & 2003 \\
\hline Clusters (villages) proposed & 100 & 100 \\
Clusters successfully reached & N/A & 81 \\
Clusters added as substitute & N/A & 2 \\
Total clusters sampled & N/A & 83 \\
Households sampled & 1290 & 1609 \\
Response rate & $65 \%$ & $80 \%$ \\
Population sampled & 7496 & 9083 \\
Population < 5 years old (\%) & $1382(18.4)$ & $1858(20.4)$ \\
Population < 15 years old (\%) & $3568(45.6)$ & $4278(47.1)$ \\
Population $\geq 65$ years old $(\%)$ & $153(2.0)$ & $153(1.7)$ \\
Male to female ratio & 0.89 & 0.92 \\
Mean household size & 5.8 & 5.6 \\
\hline
\end{tabular}

\section{Mortality}

Vital events and mortality rates for each survey period are shown in Table 2 . The 2002 survey reported 37 infant deaths ( $<1$ year), 80 child deaths ( $<5$ years) and 275 live births during the 12-month recall period. IMR was 135 (95\% CI: 73-196) per 1000 live births and U5MR was 291 (95\% CI: 209-373) per 1000 live births. Mid year underfive population was estimated at 1423 children, resulting in an under-five age specific death rate of 56 per 1000 persons per year (95\% CI 37-75). For overall mortality, 184 deaths were reported and the crude mortality rate (CMR) was 25 (95\% CI: 18-31) per 1000 persons per year, or 0.68 (95\% CI: 0.49-0.85) per 10000 per day. For the 2003 survey, mortality estimates were slightly lower for IMR, U5MR, and CMR, but not significantly different from 2002 (Table 2). There were 392 live births, 48 infant deaths, and 108 child deaths, with an IMR of 122 (95\% CI: 70-175) and a U5MR of 276 (95\% CI: 190-361). The under-five age-specific death rate was 57 per 1000 persons $(95 \%$ CI: 40-75), and the crude mortality rate was 21 (95\% CI: 15-27), or 0.58 (95\% CI: 0.41-0.74) per 10000 per day.

In order to assess the influence of response rates on mortality estimates, a stratified analysis comparing these mortality indicators in areas where the response rate was low compared with those where the response rate was

Table 2 Mid-year population estimates, vital events, and mortality rate estimates for 2002 and 2003 survey periods

\begin{tabular}{lll}
\hline & $2002 *$ & 2003 \\
\hline $\begin{array}{l}\text { Mid-year populations } \\
\quad 5 \text { years old }\end{array}$ & 1423 & 1890 \\
$\quad \geq 5$ years old & 7450 & 8994 \\
Vital events & & \\
$\quad$ Live births & 275 & 392 \\
$\quad$ Infant deaths & 37 & 48 \\
$\quad$ Under-five deaths & 80 & 108 \\
$\quad$ Overall deaths & 184 & 189 \\
Mortality rates & Estimate (95\% CI) & Estimate (95\% CI) \\
\hline Infant (IMR) & $135(73-196)$ & $122(70-175)$ \\
Child & & \\
$\quad$ U5MR & $291(209-373)$ & $276(190-361)$ \\
$\quad$ ASDR-5 & $56(37-75)$ & $57(40-75)$ \\
Overall (CMR) & $25(18-31)$ & $21(15-27)$ \\
\hline
\end{tabular}

IMR, infant mortality rate; U5MR, under-5 mortality rate; ASDR-5, under-5 age specific death rate; CMR, crude mortality rate.

*Cluster information was not available for 2002. Design effects estimated for 2003 were therefore applied to data for these years in order to account for cluster sampling design and adjust the width of confidence intervals [2003 Design Effects: IMR (2.31), U5MR (2.33), ASDR-5 (2.54), CMR (3.63)]. 


\section{T. J. Lee et al. Mortality in eastern Burma}

Table 3 Mortality indicators stratified by 'low' and 'high' coverage areas - 2002 and 2003 periods combined

\begin{tabular}{lccc}
\hline & $\begin{array}{l}\text { Low coverage } \\
\text { areas }(\mathrm{HH}=648) *\end{array}$ & $\begin{array}{l}\text { High coverage } \\
\text { areas }(\mathrm{HH}=2251) *\end{array}$ & Weighted \\
\hline Live births & 147 & 520 & N/A \\
Infant deaths & 25 & 60 & N/A \\
Under-five deaths & 51 & 137 & N/A \\
Overall deaths & 115 & 258 & N/A \\
Mortality rates & Estimate $(95 \% \mathrm{CI}) \dagger$ & Estimate $(95 \% \mathrm{CI}) \dagger$ & Estimate $(95 \% \mathrm{CI}) \dagger$ \\
Infant (IMR) & $170(107-231)$ & $116(86-145)$ & $132(104-161)$ \\
U5MR & $346(246-445)$ & $264(216-312)$ & $312(262-362)$ \\
ASDR-5 & $68(50-87)$ & $53(44-63)$ & $61(52-71)$ \\
Overall (CMR) & $29(24-34)$ & $21(18-23)$ & $26(23-29)$ \\
\hline
\end{tabular}

$\mathrm{HH}$, households; IMR, infant mortality rate; U5MR, under-5 mortality rate; ASDR-5, under-5 age specific death rate; CMR, crude mortality rate.

*A 'low' vs. 'high' response rate was defined as those areas where less than $50 \%$ and less than $80 \%$ of the proposed surveys were completed in 2002 and 2003, respectively.

†Confidence interval estimates are provided without regard to clustered design, as cluster information in the 2002 period was not collected by the BPHWT workers. higher is shown in Table 3. The 'low' stratum included those areas where $<50 \%$ and $<80 \%$ of the proposed surveys were completed in 2002 and 2003, respectively. In all instances, the combined mortality estimate across the 2 years was higher in areas where security concerns and unreachable clusters resulted in low response rates. A weighted analysis including estimates of mortality adjusted as if all areas reported $100 \%$ response rates also produces higher mortality estimates (Table 3 ).

A population pyramid for the more complete survey (2003) is shown in Figure 2 (the 2002 pyramid had a similar structure). During the two survey periods, there were 89 and 92 males, respectively, for every 100 females in the 15-45 years age group. There were, however, no significant differences in mortality rates between males and females for either survey period.

\section{Cause of death}

Cause of death was reported for $166(90.2 \%)$ and 173 $(91.5 \%)$ deaths in the 2002 and 2003 surveys, respectively. The distribution of causes was similar for both periods, with fewer deaths because of landmines/other violence and more diarrhoea deaths reported in the 2003 survey.
Figure 2 Population pyramid for population sampled during 2003 survey period.

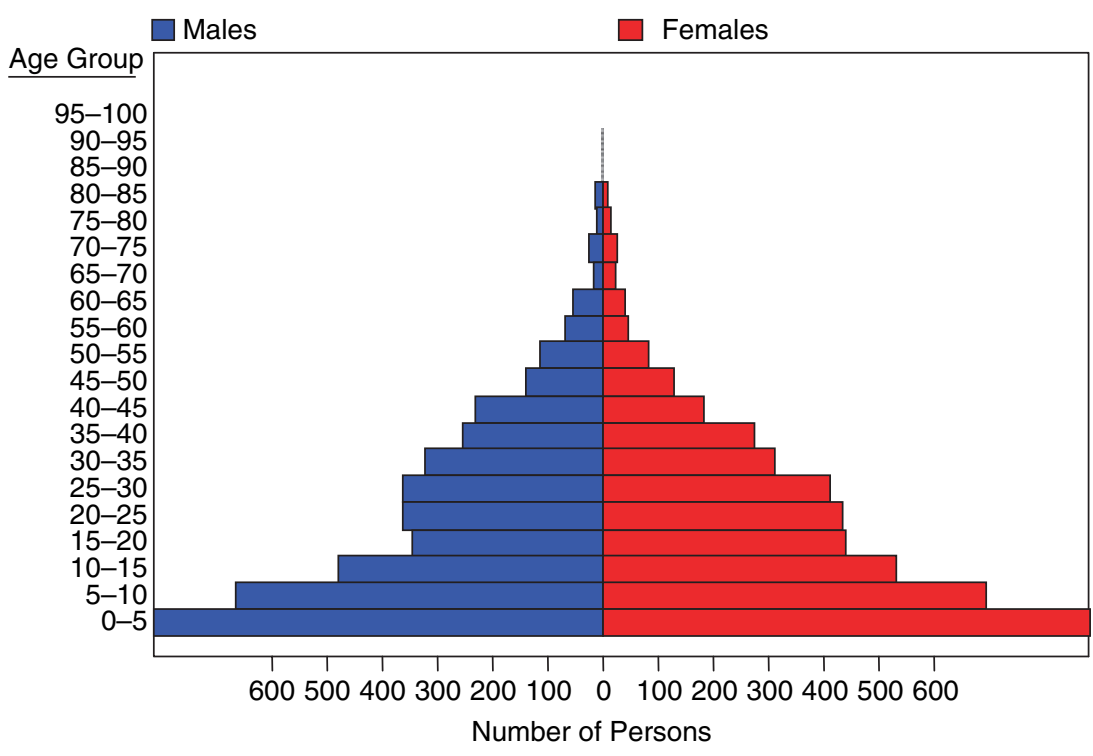




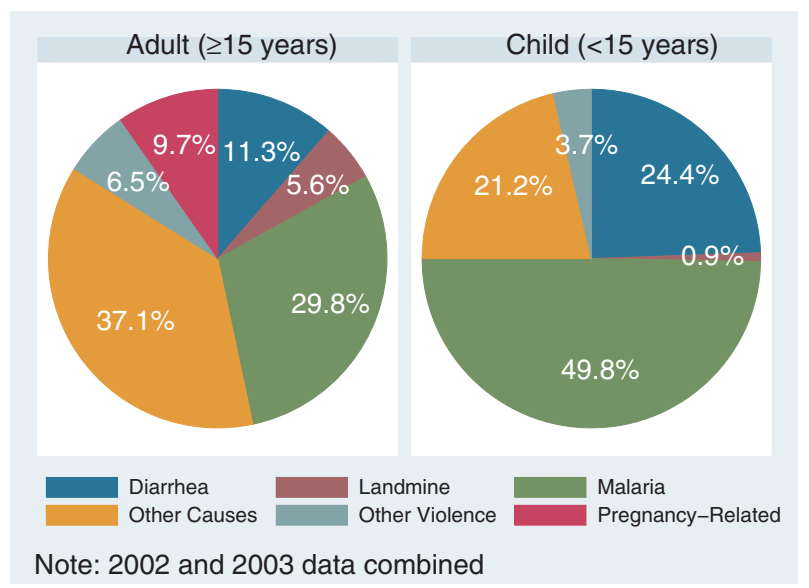

Figure 3 Reported cause of death, by age group.

However, there was insufficient power to detect differences in cause-specific mortality between the periods. In both periods, the most common reported cause of mortality was malaria, with $74(45 \%)$ and $71(41 \%)$ deaths attributed in 2002 and 2003, respectively. Other reported causes in 2002 included diarrhea (15\%), landmines (4\%), and other violent causes $(6 \%)$. Among adult females, a high proportion of deaths were attributed to pregnancy-related causes. Seven $(23 \%)$ of the 30 adult female deaths in 2002, and five $(36 \%)$ of the 14 deaths reported in 2003 were pregnancy related. For both periods, more than one quarter of deaths were attributed to a non-specified alternative cause of death. The combined data on cause of death is shown in separate pie charts for adult ( $\geq 15$ years) and child (<15 years) deaths (Figure 3 ).

\section{Discussion}

The infant (IMR = 122-135) and child (U5MR = 276291) mortality rates reported here are significantly higher than estimates for Burma as a whole (IMR $=76$, $\mathrm{U} 5 \mathrm{MR}=107,2003$ data, UNICEF 2005). Although higher peak mortality rates have been reported from other areas of the world, the rates from this population in eastern Burma are striking within the context of Southeast Asia. Cambodia reported 140 as the highest U5MR among ASEAN countries, while adjacent Thailand reported a U5MR of 26 (UNICEF 2005).

There are several potential limitations to address. The most significant is the low response, which although improved in 2003, most likely resulted in an underestimate of mortality rates. One would expect that villagers who could not be accessed because of displacement or security constraints would have higher mortality rates. The stratified and weighted analyses support this premise by demonstrating higher mortality rates in areas with lower return rates (Table 3 ). Health workers also replaced two nearby villages for displaced villages in 2003; these substitutions may also contribute to underestimation of the true mortality rates.

Reliance on respondent-reported cause(s) of death is problematic. While reports of traumatic injuries such as landmines are more likely to be accurate, the indigenous population attributes most fever to malaria. Our finding that the most common cause of death was attributed to malaria is consistent with BPHWT clinical disease surveillance and other health services along the Thai-Burma border; nevertheless, it should be interpreted with caution. Formal verbal autopsies would improve accuracy but require substantial time and training.

Recall bias is a common problem with mortality surveys. Because both malaria and conflict (more frequent during dry season in this population) have strong seasonal variation, a 1-year recall period was chosen to minimise seasonal fluctuations in mortality. Although a longer recall period can lead to an underestimate of deaths (Depoortere et al. 2004), a shorter period using a more recent 'anchoring' date can lead to increase in seasonal bias, and also effectively decreases the sample size for vital events. Interviewer training in the use of well-known dates as reference points can minimise recall bias.

It is not standard practice to apply design effects from 1 year to another, even in the same population using the same $100 \times 20$ survey design. We applied the 2003 design effects as a best estimate, given the lack of cluster information in 2002. Presentation of mortality rates in the first survey (2002) without adjusting for design effect would overestimate the precision of the estimates. We could have excluded the 2002 survey, but given the extreme logistical constraints under which these data were collected, a presentation of data from two consecutive surveys showing similar results provides one means to gauge the internal consistency and validity of the data.

Despite these limitations, there are several methodological approaches in these surveys that may contribute to health assessment efforts in conflict and other inaccessible settings. First, BPHWT did not exclude areas from the sampling frame because of security constraints or inaccessibility, as in other surveys (CDC 2002; Coghlan 2006). The low response rates resulted from BPHWT's attempt to reach even the most insecure and inaccessible areas. Although this presents a potential bias, the stratified and weighted analyses provide methods to gauge this influence, whereas the a priori exclusion of areas creates a bias, which is difficult to assess. Furthermore, the a priori exclusion is 
not always possible as insecure areas in this and other conflict zones are often dynamic.

The survey also modified the commonly used WHO/EPI $30 \times 30$ method (Bennett et al. 1991). Although the clusters were selected proportionate to population size according to standard methods, a $100 \times 20$ design was chosen because past experience had proven that a substantial proportion of villages would be inaccessible due to security concerns. This increase in the number of clusters and decrease in cluster size reduced the proportional impact of losing any given cluster. Increasing the number of clusters has also been suggested as a means to reduce design effects (Coghlan 2006), as the standard WHO/EPI method often results in design effects greater than two (Roberts et al. 2003, Coghlan 2006).

The survey also used systematic sampling for selecting households within clusters instead of the standard $\mathrm{WHO} /$ EPI proximity method in order to improve the precision of estimates. The mobile health workers were able to accomplish this because all of the villages in the population are reasonably small enough for interviewers to walk through the entire village. As suggested by Coghlan et al. (2006), both increasing clusters and systematic sampling are methodological improvements that could be considered by mortality surveys, but need to be weighed against the increases in time, resources, and risk to personnel.

While the methods described above are not unusual, the use of indigenous mobile health worker teams is rare. Although they have collected health data since 1998 for internal programmatic use, one potential concern is that these surveyors, as members of the sampled communities, could bias results. In this context, however, no other viable options were available. External surveyors would have to enter and travel through the conflict zones illegally at great risk, and would not have the necessary local knowledge and skills to traverse the terrain and avoid military troops. The health workers have several advantages for conducting surveys in this population: they have a high level of familiarity with local communities, are highly trusted by the villagers, and visit all communities in the course of their normal work. These factors make them excellent surveyors for assessment of mortality and other health indicators, a task they accomplish with minimal additional resources.

Although multiple factors may contribute to these high mortality rates, the impact of conflict is unmistakable. The shortage of males in the 14-45 year old age group (88-92 males per 100 females) is typical for conflictaffected populations. This ratio is similar to that reported among Afghan refugee populations in Pakistan $(88: 100)$ (Yusaf 1990) but less extreme than reported among families of former rebels in Angola (80:100) (Grein et al. 2003). This compares starkly with national statistics reporting a male to female ratio of $98: 100$ (UNDP 2001). Other markers of conflict include the high incidence of landmines and other violence-related deaths, attributed to $10 \%$ and $6 \%$ of total deaths in 2002 and 2003 , respectively. Landmines alone accounted for $2.4 \%$ of all deaths (combined 2002 and 2003 data).

Beyond direct conflict-related deaths, this survey supports the evidence that higher death rates in protracted conflict settings are caused by preventable infectious diseases rather than violence (CDC 1992, 2002; Coghlan 2006). The preponderance of reported deaths attributable to malaria is likely due in part to poor access to health services and high levels of displacement (Burmese Border Consortium 2004), factors that have been strongly linked to malaria-related morbidity and mortality (SinghanetraRenard 1986, 1993; Bloland \& Williams 2003). Thus, the elevated malaria deaths could be considered indirect outcomes of this conflict.

Pregnancy-related deaths were also a significant contributor to overall mortality. Twenty seven per cent of adult female deaths were pregnancy-related (combined 2002 and 2003 data). Although the sample was not large enough to calculate a stable estimate and confidence interval, the absolute number would indicate an extremely high maternal mortality ratio in this population. Potential reasons for this were elucidated in an unpublished 2002 BPHWT reproductive health survey: $94 \%$ of deliveries occurred in the home or jungle, $4 \%$ of women had access to emergency obstetric care, and only $35 \%$ had more than one antenatal care visit. As with malaria, maternal mortality may be intimately linked to the indirect effects of conflict (McGinn 2000).

\section{Conclusion}

We describe a population with high rates of ongoing mortality. Confirmatory studies must be performed to describe mortality rates over a larger area, and to monitor the situation over time. Difficulties with access, lack of resources, and apprehension about data limitations has lead to considerable under-reporting of mortality from this and other populations living within conflict zones. This paucity of information prevents the international community from acting with a precise awareness of the severe health conditions existing within these areas. Moreover, the effect is to significantly reduce resources and attention from the international community. Currently there are no governmental or international non-governmental organisations working in this population from within Burma, and organisations registered to provide support for refugees in Thailand are not permitted to also provide cross-border assistance. Health strategies need to be developed to 
transcend border issues, and international aid to the Burmese government should be accompanied by assurances that relief efforts will reach populations with the greatest need.

\section{References}

Assefa F, Jabarkhil MZ, Salama P et al. (2001) Malnutrition and mortality in Kohistan District, Afghanistan, April 2001. The Journal of the American Medical Association 286, 2723-2728.

Bennett S, Woods T, Liyanage WM et al. (1991) A simplified general method for cluster-sample surveys of health in developing countries. World Health Statistics Quarterly 44, 98-106.

Bloland PB \& Williams HA (2003) Malaria and mobility - a brief history and overview. Malaria Control During Mass Population Movements and Natural Disasters. National Academies Press, Washington, DC.

Boss LP, Toole MJ \& Yip R (1994) Assessments of mortality, morbidity, and nutritional status in Somalia during the 19911992 famine. Recommendations for standardization of methods. The Journal of the American Medical Association 272, 371-376.

Burmese Border Consortium (2004) Internally Displacement and Vulnerability in Eastern Burma. Burmese Border Consortium, Thailand.

CDC (1992) Famine-affected, refugee, and displaced populations: recommendations for public health issues. Morbidity and Mortality Weekly Report 41 (no. RR-13).

CDC (2002) Elevated Mortality Associated with Armed Conflict Democratic Republic of Congo. Morbidity and Mortality Weekly Report 52, 469-471.

Checchi F, Elder G, Schäfer M et al. (2002) Consequences of armed conflict for an ethnic Karen population. Lancet 362, 7475.

Chelala C (1998) Burma: a country's health in crisis. Lancet 352, 556.

Coghlan B, Brennan RJ, Ngoy P et al. (2006) Mortality in the Democratic Republic of Congo: a nationwide survey. Lancet 367, 44-51.

Depoortere E, Checchi F, Broillet F et al. (2004) Violence and mortality in West Darfur, Sudan (2003-2004): epidemiological evidence from four surveys. Lancet 364, 1315-1320.
Gessner B (1994) Mortality rates, causes of death, and health status among displaced and resident populations of Kabul, Afghanistan. The Journal of the American Medical Association 272, 382-385.

Grandesso F, Sanderson F, Kruijt J et al. (2005) Mortality and malnutrition among populations living in South Darfur, Sudan: results of 3 surveys, September 2004. The Journal of the American Medical Association 293, 1490-1494.

Grein T, Checchi F, Escriba JM et al. (2003) Mortality among displaced former UNITA members and their families in Angola: a retrospective cluster survey. BMJ 327, 650 .

McGinn T (2000) Reproductive health of war-affected populations: what do we know? International Family Planning Perspectives 26, 174-180.

Roberts L \& Despines M (1999) Mortality in the Democratic Republic of Congo. Lancet 353, 2249-2250.

Roberts L, Lafta R, Garfield R et al. (2004) Mortality before and after the 2003 invasion of Iraq: cluster sample survey. Lancet 364, 1857-1864.

Roberts L, Ngoy P, Mone C et al. (2003) Mortality in the Democratic Republic of Congo: results from a nationwide survey. International Rescue Committee, New York.

Salama P, Assefa F, Talley L et al. (2001) Malnutrition, measles, mortality, and the humanitarian response during a famine in Ethiopia. The Journal of the American Medical Association 286, 563-571.

Singhanetra-Renard A (1986) Population movement, socioeconomic behavior and the transmission of malaria in northern Thailand. The Southeast Asian Journal of Tropical Medicine and Public Health 17, 396-405.

Singhanetra-Renard A (1993) Malaria and mobility in Thailand. Social Science \& Medicine 37, 1147-1154.

The World Food Programme (2004) UN warns of child malnutrition in Myanmar. Agence France Presse, September 14, 2004.

UNDP (2001) Human Development Indicators. Human Development Report, UNDP 2001. Oxford UP, New York.

UNICEF (2005) The State of the World's Children 2005. UNICEF, New York.

Yusaf F (1990) Size and demographic characteristics of the Afghan refugee population in Pakistan. Journal of Biosocial Science 22, 269-279.

Corresponding Author Thomas J. Lee, UCLA School of Medicine, UCLA Emergency Medicine Center, 924 Westwood Blvd, Suite 300, Los Angeles, CA 90024, USA. Tel.: +1-310-280-0987, Fax: +1-310-919-2800, E-mail tomlee@ucla.edu 


\section{T. J. Lee et al. Mortality in eastern Burma}

Taux de mortalité en zones de guerre dans les états de Karen, Karenni et Mon dans l'est du Burma

objectifs Estimer les taux de mortalité pour les populations vivant dans les zones de guerre civile dans les états de Karen, Karenni et Mon dans l'est du Burma.

MÉTHODEs Des agents de santé mobiles locaux procurant des soins dans les zones de guerre dans les régions de Karen, Karenni et Mon dans l'est du Burma ont mené des enquêtes sur des échantillons en grappe, en interviewant des chefs de familles sur des périodes de trois mois entre 2002 et 2003 , afin de collecter des données démographiques et de mortalité.

RÉSULTATS En 2002 les agents de santé ont réalisé 1290 enquêtes de familles comprenant 7496 individus. En 2003, 1609 familles avec 9083 individus ont été interviewées. Les statistiques vitales suivantes ont été estimées: taux de mortalité infantile: 135 (IC95\%: 96-181) et 122 (IC95\%: 70-175) pour 1000 naissances vivantes; taux de mortalité pour les moins de 5 ans: 291 (IC95\%: 238-348) et 276 (IC95\%: 190-361) pour 1000 naissances vivantes; taux de mortalité générale: 25 (IC95\%: 21-29) et 21 (IC95\%: 15-27) pour 1000 personnes par année.

ConcLusions Les populations vivant dans les zones de guerre dans l'est du Burma connaissent des taux élevés de mortalité. L'utilisation d'agents de santé mobiles locaux procure des moyens pour la mesure de l'état de santé des populations qui normalement auraient été inaccessibles à cause de la guerre.

mots clés Burma, mortalité, personnes déplacées à l'intérieur, malaria, mines antipersonnelles, guerre civile

Tasas de mortalidad de zonas en conflicto en los estados de Karen, Karenni, y Mon, en Birmania oriental

овјетіvos Estimar las tasas de mortalidad de las poblaciones que habitan áreas en guerra civil en los estados Karen, Karenni y Mon de Birmania oriental.

мÉTodos Los trabajadores sanitarios indígenas ambulantes, encargados de prestar cuidados médicos en las zonas en conflicto de los estados de Karen, Karenni y Mon, realizaron encuestas en una muestra por conglomerados, entrevistando a las cabezas de familia durante periodos de tres meses entre el 2002 y 2003, con el fin de recolectar datos demográficos y de mortalidad.

RESUltados Durante el 2002, los trabajadores sanitarios completaron 1290 encuestas, incluyendo 7496 individuos. En el 2003 se encuestaron 1609 hogares con 9083 miembros. Los cálculos de estadísticas vitales fueron los siguientes: tasa de mortalidad infantil 135 (95\%CI: 96-181) y 122 (95\%CI: 70-175) por cada 1000 nacidos vivos; tasa de mortalidad en menores de cinco años: 291 (95\%CI: 238-348) y 276 (95\%CI: 190-361) por cada 1000 nacidos vivos; tasa cruda de mortalidad: 25 (95\% CI: 21-29) y 21 (95\%CI: 15-27) por cada 1000 nacidos vivos por año.

CONCLUSIONES Las poblaciones que viven en zonas conflictivas de Birmania oriental experimentan unas tasas de mortalidad altas. El uso de trabajadores sanitarios indígenas ambulantes proporciona una manera de medir el estado de salud en poblaciones que normalmente serían inaccesibles debido a un conflicto en curso.

palabras clave Birmania, mortalidad, personas internamente desplazadas, malaria, minas antipersonales, guerra civil 